BMJ Open Gastroenterology

\title{
Severe colic mimicking intussusception: a new phenomenon
}

\author{
Mohamed Amin El-Gohary
}

To cite: El-Gohary MA. Severe colic mimicking intussusception: a new phenomenon. BMJ Open Gastro 2015;2:e000023. doi:10.1136/bmjgast-2014000023

- Additional material is available. To view please visit the journal (http://dx.doi.org/ 10.1136/bmjgast-2014000023).

Received 24 October 2014 Revised 25 November 2014 Accepted 15 December 2014
Division of Paediatric Surgery, Department of Surgery, Burjeel Hospital, Abu Dhabi, UAE

\section{Correspondence to} Dr Mohamed Amin ElGohary; amingoh@gmail.com

\section{ABSTRACT}

Objective: To highlight a new phenomenon that we have encountered in children during the past 5 years. Children in this group have a pathognomonic clinical picture of sudden acute severe abdominal colic during which the child is continuously screaming for 1-2 min. All these patients were initially diagnosed on clinical and ultrasonographic grounds as acute intussusception. Careful interpretation of the radiological findings revealed faecal impaction of the terminal ileum and caecum.

Design: This is a retrospective study looking at children presenting between 2009 and 2014 with acute severe abdominal colic pain. These were 11 patients aged 9 months to 5 years. We reviewed our experience in the management and diagnosis of these patients.

Result: All patients were diagnosed initially as intussusception, which was confirmed by ultrasonography (US). US revealed an appearance mimicking intussusception, 3 cases of which were intermittent. This US appearance proved to be a hard stool filling the terminal ileum. In all patients, abdominal X-ray revealed stool at the right side of the colon filling the caecum. Diagnostic gastrografin enemas that were performed in four patients excluded intussusception and confirmed stool at the caecum and ascending colon. In none of those patients had contrast passed into the terminal ileum. There was dramatic response to fleet and/or gastrografin enemas. Five patients required a second dose of enema and two patients required three doses.

Conclusions: We highlight a new phenomenon of severe abdominal pain caused by faecal impaction of the terminal ileum and caecum. Increased awareness of this condition helps to avoid unnecessary investigations and/or surgical exploration.

\section{INTRODUCTION}

Abdominal pain and/or colic are common symptoms in the paediatric age group, the causes of which depend on age and associated symptoms. In the past, intussusception remained the primary cause of abdominal colic in children below 2 years of age. Constipation is known to be associated with abdominal pain, but has not been known to be severe enough to warrant urgent attention. All the patients in this report presented

\section{Summary box}

What is already known about this subject

- Constipation is a known cause of abdominal pain, but it has never been thought to be severe enough to present with acute abdominal colic.

- Intussusception is associated with abdominal colic, but needs to have other criteria to confirm the diagnosis.

- Ultrasound remains the best non-invasive diagnostic modality for abdominal pain and/or colic.

- The patients in our group have common symptoms of acute severe agonising abdominal colic with ultrasound picture suggestive of intussusception.

What are the new findings

- We have, in the past, reported a case of caecal faecalith that presented with abdominal colic, which was diagnosed as intussusception on radiological ground that required surgical intervention.

- The cause of this new phenomenon is likely to be related to the intermittent obstructive effect of hard stool at the caecum and terminal ileum.

- As far as we can ascertain, we have not encountered a similar clinical picture in the literature.

How might it impact on clinical practice in the foreseeable future?

- We hope that by highlighting this phenomenon it might help to avoid unnecessary surgical intervention due to misdiagnosis.

with sudden recurrent severe colicky abdominal pain, during which they screamed in agony for 1-2 min, with the pain ending abruptly. We have learned from earlier experience with similar cases to be cautious in labelling these types of cases as intussusception and to treat them conservatively with enemas.

\section{MATERIALS AND METHODS}

Between 2009 and 2014 we encountered 11 children aged 9 months to 5 years who presented with sudden, severe colicky abdominal pain, associated with agonised screaming and contortions (see online supplementary 
video). Two patients were under 1 year of age, five under 2 years and two aged 4 and 5 years, respectively. These attacks tend to stop abruptly only to recur after a variable period of a few minutes to an hour. Abdominal examination during the attack is difficult and shows generalised guarding. Per rectal (PR) examination revealed an empty rectal vault and in two patients there were stains of fresh blood on the examining finger. In two other patients there was a non-tender mass about $3 \mathrm{~cm}$ in size at the right iliac fossa. US imaging initially reported as intussusception with a mass at the terminal ileum pushing itself into the caecum. These findings were witnessed together with the radiologists during the attacks, three of which were intermittent (figure 1). Gastrografin enemas used in the three cases revealed faecal matter filling the right colon and caecum, which failed to reflux into the terminal ileum (figure 2). Plain X-ray showed stool filling the right side of the colon and caecum (figure 3). None of those patients was operated on and all responded to fleet and/or gastrografin enemas.

\section{DISCUSSION}

Constipation is by far the commonest cause of abdominal pain. ${ }^{1-3}$ However, the pain associated with constipation is usually chronic in nature and never presents with acute episodes of severe abdominal colic that warrants urgent attention. Rectal faecal impaction may present with severe pain, ${ }^{4}$ but is readily excluded by PR examination. In 1981, we reported a case of severe abdominal pain diagnosed clinically and radiologically as intussusception, but it proved during exploration to be a case of impacted caecal faecalith. ${ }^{5}$ This has prompted us to think twice before labelling patients with severe abdominal colic as intussusception before excluding faecal impaction at the caecum and terminal ileum. The pathognomonic clinical presentation in this group of patients is severe abdominal colic with screaming and contorting. No analgesic or anticholinergic have had

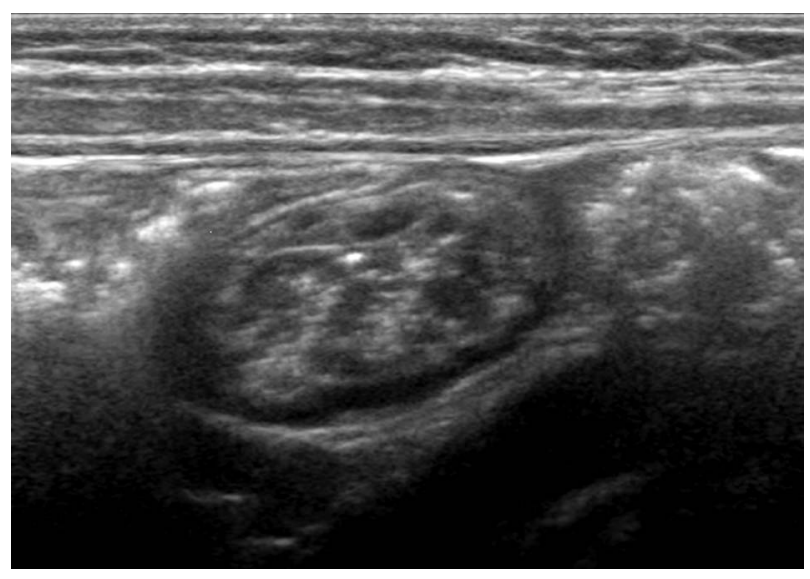

Figure 1 Faecal mass inside terminal ileum mimicking intussusception.

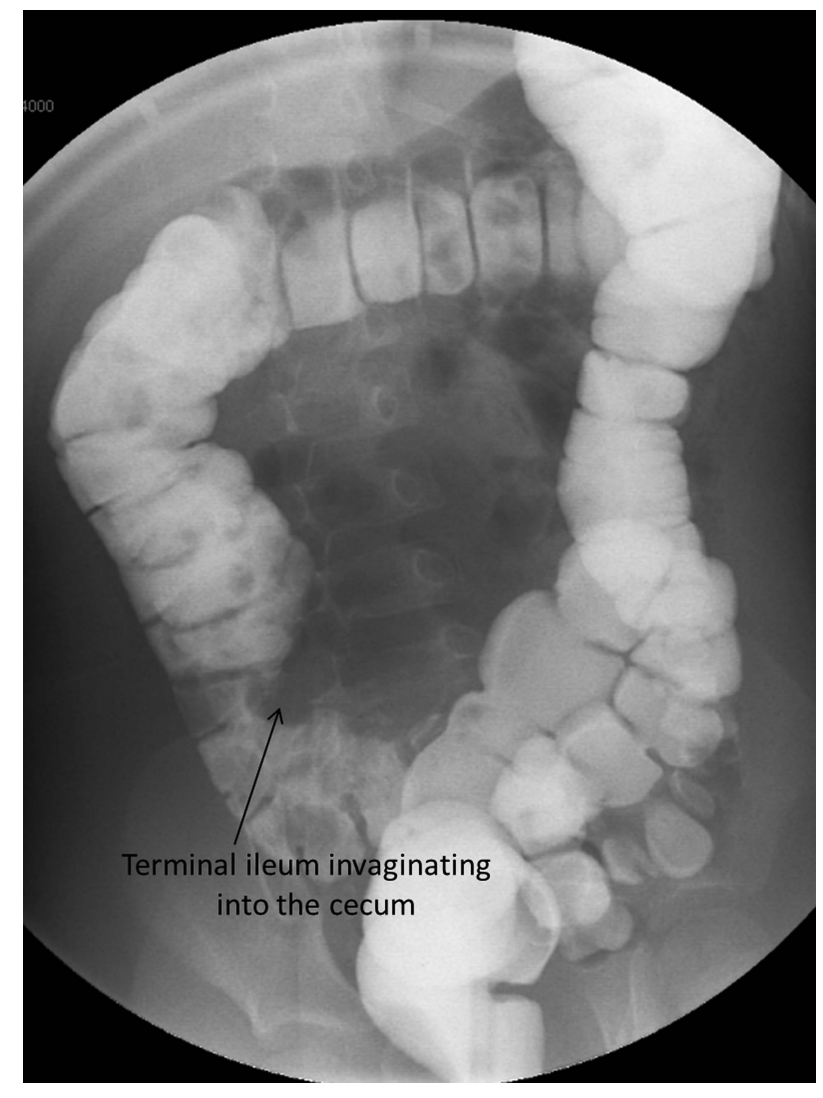

Figure 2 Gastrografin enema showing faecal matter in the caecum with indentation of the terminal ileum.

any effect on alleviating these episodes of severe colicky pain. Many of the parents questioned our working diagnosis as simply related to caecal impaction, but were

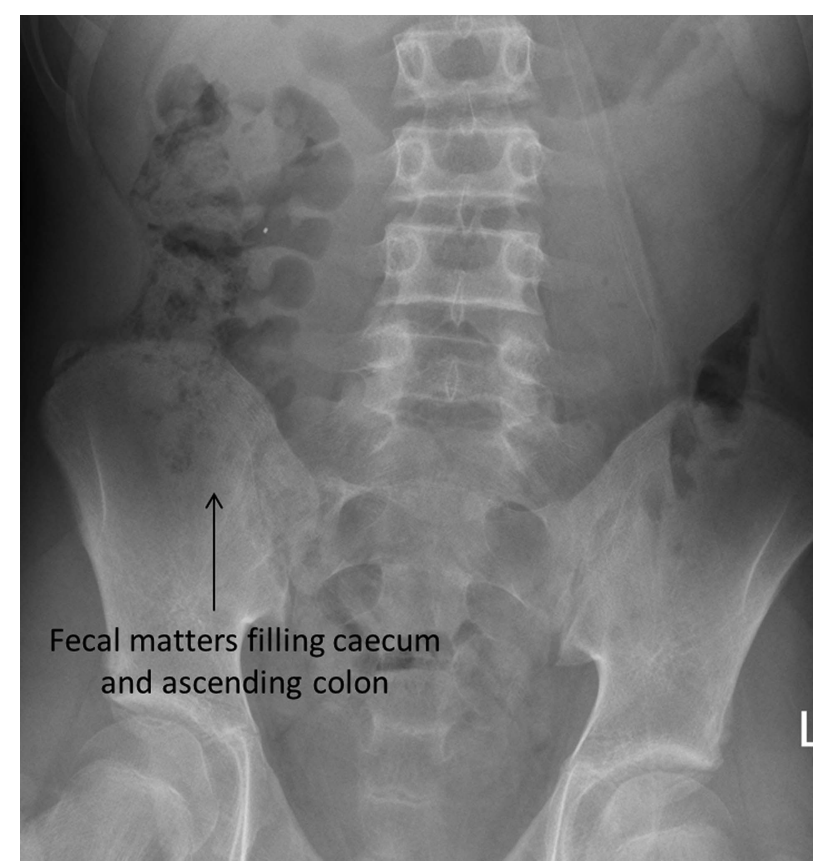

Figure 3 Plain X-ray of the abdomen showing faecal matter in the right side of the colon and caecum. 
pleased to see the dramatic response to enemas. The explanation might be related to the fact that the faecalith at the terminal ileum and/or caecum acts as intermittent bowel obstruction causing the bouts of abdominal colic. The mass that was palpable in three patients at the right iliac fossa is different from the classic intussusception where the right iliac fossa is empty and mass felt at right subhepatic area or epigastrium. The fresh bleeding that was encountered in two of our patients may be related to the mechanical effect of the hard stool against the bowel mucosa. As far as we can ascertain, we have not come across any similar pathology in the literature. We hope that highlighting this condition will attract attention among doctors towards this new phenomenon, thus avoiding unnecessary investigation and/or surgery.

\section{CONCLUSION}

We would like to attract attention towards a new phenomenon that presents with severe abdominal colic mimicking intussusception and which is caused by simple faecal impaction of the terminal ileum and caecum.
Funding This research received no specific grant from any funding agency in the public, commercial or not-for-profit sectors.

Competing interests None.

Provenance and peer review Not commissioned; externally peer reviewed.

Data sharing statement No additional data are available.

Open Access This is an Open Access article distributed in accordance with the Creative Commons Attribution Non Commercial (CC BY-NC 4.0) license, which permits others to distribute, remix, adapt, build upon this work noncommercially, and license their derivative works on different terms, provided the original work is properly cited and the use is non-commercial. See: http:// creativecommons.org/licenses/by-nc/4.0/

\section{REFERENCES}

1. Loening-Baucke V, Swidsinski A. Constipation as cause of acute abdominal pain in children. J Pediatr 2007;151:666-9.

2. Altamimi E. Clinical characteristics of pediatric constipation in South Jordan. Pediatr Gastroenterol Hepatol Nutr 2014;17:155-61.

3. Shah N, Baijal R, Kumar P, et al. Clinical and investigative assessment of constipation: a study from a referral center in western India. Indian J Gastroenterol. Published online 15 Oct 2014. doi:10.1007/s12664-014-0505-8

4. Chang L, Lembo AJ, Lavins BJ, et al. The impact of abdominal pain on global measures in patients with chronic idiopathic constipation, before and after treatment with linaclotide: a pooled analysis of two randomised, double-blind, placebo-controlled, phase 3 trials. Aliment Pharmacol Ther 2014;40:1302-12.

5. Gohary A, Shepherd DF, Freeman NV. Cecal fecalith mimicking intussusception. Z Kinderchir 1981;33:363-6. 